\title{
Scientific Culture and Economic Growth in the Long-Run: On a Capital Perspective
}

\author{
Pei-xiao Qi ${ }^{1} \&$ Nian Zheng ${ }^{1}$ \\ ${ }^{1}$ Department of Science Popularization Policy, China Research Institute for Science Popularization, Beijing, China \\ Correspondence: Pei-xiao Qi, Department of Science Popularization Policy, China Research Institute for Science \\ Popularization, No. 86, College South Road, Haidian District, Beijing, China.
}

Received: March 26, 2018

Accepted: April 9, 2018

Online Published: April 19, 2018

doi:10.5430/rwe.v9n1p39

URL: https://doi.org/10.5430/rwe.v9n1p39

\begin{abstract}
The cultural capital can be as a kind of asset that embodies, stores and produces the cultural values except for producing the economic values. With the further progress of modern civilization, scientific culture, on an economics perspective, as a combination of intangible and tangible capital, more and more becomes the one of important engine to make economic sustainable growth in the long run for a country. Based on the framework by Barro and Turnvosky, this paper constructed an economic growth model including the factor of scientific culture and mainly found that the impact of scientific culture capital growth rate on human capital accumulation is positive, and then affects economic growth rate. And the greater scientific culture capital growth rate influences the human capital accumulation, the higher economic growth rate is.
\end{abstract}

Keywords: scientific culture, tangible capital, intangible capital, factor input, economic growth

\section{Introduction}

Ernst Cassirer, a German philosopher, said that science is the last step of human intelligence development and the highest and most unique achievement of human culture....... and there isn't any second force to surpass scientific thought (Ernst, 2013). Scientific culture is a unity of internalization and externalization of human spirit and a typical kind of advanced culture. Generally, scientific culture is a value system about scientific values, spirits, beliefs, conventions, attitudes and methods within the scientific community after institutionalization and customization of society. Pickering (1995) pointed out scientific culture factually consists of a number of different elements or even some heterogeneous elements. Godin \& Gingras (2000) pointed out that scientific culture is a form which individual and society occupy all modes of science and technology.

Scientific culture is the crystallization of material culture and spiritual culture and its behavior criterions and values importantly embody the progress of human civilization. Scientific culture is also a catalyst to make traditional culture continuously updating and modernizing. Scientific culture emerged and developed based on a certain cultural background and at the same time had become a very important element to affect the changes and evolutions of different cultures. Considering the real value of scientific culture, Francis Bacon thought that scientific culture in fact is a far-sighted and collaborative social activity which can effectively better people's lives; there is nothing significant like invention of new technologies and products in every social welfare can be given to human (Hanbury, 1998).

In addition, economists found that well understanding culture is better at understanding economic development. David Landes pointed out Max Weber even said that if we knew everything based on history of economic development, cultural differences made economic development history of different countries have their own characteristics (Lawrence \& Samuel, 2000). The President Xi Jinping (2017) pointed out that it must excite nation's culture innovation and creation vitality to build a strong socialist culture country. Yoshihara Kunio, a Japanese economist, thought that Japan can rapidly develop because it has a suitable culture background (Lawrence, 2006). Jeffrey Sachs, even a skeptic to culture, also recognized the cultural influences. His work The End of Poverty wrote that the government has been making effort to develop its country but culture environment may be an obstacle to development process (Sachs, 2005). 


\section{Social Economic Function of Scientific Culture}

Science \& technology innovation can make a country stronger. But science \& technology innovation not only needs human capital but a better social environment. Environment can bring up and also strangle talents, at the same time, can stimulate and also hinder innovation. In fact, social environment is a cultural background of developing science $\&$ technology innovation and the cultural background is called "scientific culture". Innovation is to improve the level of science and technology. But innovation development cannot be separated from the scientific culture environment, which is advantageous to development of cultural industries can promote economic multi-polar growth.

On a sociology perspective, scientific culture can promote social development and reform. Science \& technology has become a decisive factor in economic and social development. It has a revolutionary impact on not only social production efficiency, product quality, diversity, production and management mode but also social economic structure, people's lifestyle and social concept.

In cultural economics field, there is a found that culture development - investing culture - can promote the economic growth in the long-run and culture capital investment is one of important engines to maintain the long-run growth for economy. Therefore, scientific culture construction is an engine to promote the development and prosperity of cultural industries.

Early $21^{\text {st }}$ century, information technology industries underwent a stage from peak to trough. After that, taking advantage of rapid development of science \& technology, the big data market scale in the world was 28.1 billion USD in 2016 , increasing by $22 \%$ compared with 2015 , it is predicted that the big data market scale in the world will be about 97 billion USD in 2027. (Note 1) Computer and mobile games have been one of the most important entertainment industries. Anime industry, as one of mainstay cultural industries in America and Japan, embodies directly soft power of scientific culture. In 2003, Time pointed out our world would step into a new era of digital entertainment around 2015. So, with the development of modern cultural industries, science \& technology innovation plays an important leading role in the development of cultural industries. The scientificalization and technicalization of culture will be an inevitable trend of coordinated development of science \& technology and culture in the new era. Therefore, scientific culture is a potential capital force to promote the development of cultural industries.

Cultural industries have become more and more important for economic development. Some large-scale production industries, for example, movie, music, radio, publishing and printing industries have been gradually emerging (Throsby, 2008), which directly improves economic growth. In addition, cultural industries play a potentially indirect role in promoting economic growth (Florida, 2002, 2005; Santagata, 2002). The externality of cultural industries can affect other production sections to stimulate economic development. Cultural value and cultural environment generated by developing cultural industries can stimulate the emergence of other new ideas and new technologies. Otherwise, developing cultural industries can also improve residents' life quality and even enterprises' competitiveness.

In fact, there were many scholars from economic and cultural field thought culture is the core of human capital. Costanza \& Daly (1992) pointed out culture capital is one of important elements consisting of human capital which is an experience accumulation of scientific and cultural knowledge and technical ability. Zweigenhaft (1993) used culture capital instead by human capital as in his research on how culture capital and social capital to influence graduate behavior in Harvard University. A Chinese scholar Liu Xielin pointed out it is the R\&D input and talent to decide enterprise innovation ability in recent time, it is the strategy and management in the mid-term and it is the institution and culture in the long run. (Note 2) In 1995, there were 3.5 million jobs provided by culture and arts departments in Europe and over 2\% labor employed in these departments (European Commission, 1998; Greffe, 1999). In 1997, there was 5.3\% of urban labor working in movie industry in Los Angeles (Santagata, 2002).

It should be realized that scientific culture is as a capital, combination with other capital, can produce more products and services. Throsby (2001) thought the cultural capital can be as a kind of asset that embodies, stores and produces the cultural values except for producing the economic values (Throsby, 2008). But scholars still don't totally understand which way culture capital to affect economic growth (Sacco \& Segre, 2009), so Sacco \& Segre (2009) provided a mode that can promote economic growth by sustainably investing culture. And the New Economic Growth Theory points out human capital is a key factor in many possible elements which promote economic growth. Therefore, based on economic growth theory, this paper tries to analyze the relationship between scientific culture, as a capital - one of important factors influencing human capital, and economic growth.

\section{Economic Growth Model Including Scientific Culture Capital}

Generally, people with higher cultural level and creativity have relatively higher incomes and have more chances to 
participate in many social activities, which will increase the marginal consumption tendency of local culture products and services and further promote the development of local economy. And the accumulation of scientific culture capital has a positive influence on economic growth through human capital.

Recently, it is not clearly stated that what role scientific culture capital plays in economic growth in growth theory. Usually, it is thought that the accumulation of other input factors, such as labor (technical or non-technical) and capital (mainly physical capital, human capital and technical capital), lead to long-run economic growth except scientific culture capital. Therefore, this paper constructed an economic growth model (Note 3) including the factor of scientific culture and analyzed if scientific culture can promote economic growth.

\subsection{Firms Behavior}

Consider a closed economy. Consumption goods are the numeraire goods which are produced perfectly competition by lots of firms with small and structurally-identical. So, the representative firm's Cobb-Douglas production function with technological parameter $T$ as following:

$$
Y_{t}=T_{t} \cdot S C_{t}^{\beta} \cdot H_{Y_{t}}^{\alpha}
$$

Where $S C_{t}$ is the stock of scientific culture capital at $t . T_{t}>0$, is a positive technological parameter at $t$. $\alpha+\beta=1$ and $\alpha, \beta \in(0,1), \alpha, \beta$ are respectively the human capital and scientific culture capital contribution rates in economic growth. $H_{Y_{t}}=\xi_{t} \cdot H_{t}$ and $\xi_{t} \in(0,1), H_{Y_{t}}$ is the total amount of human capital to produce goods at $t, H_{t}$ is the total amount of human capital at $t, \xi_{t}$ is the proportion of human capital devoted to goods production in total human capital at $t . Y_{t}$ is the final output at $t$.

In the long-run, along the balanced growth path equilibrium, $\xi_{t}$ converges to a constant, that is $\lim _{t \rightarrow+\infty} \xi_{t}=c, \forall$ $t, \xi_{t}=\xi$. When perfect competition, there are a large number of small, structurally-identical firms producing the structurally-identical goods, the representative firm cannot influence the technological progress level of the whole economy system. So $T_{t}$ is the average technological progress level. It assumes that $T_{t}$ depends on the relative intensity of scientific culture capital at the whole economy system, that is the ratio of the scientific culture to human capital, $\frac{S C_{t}}{H_{t}}$. We assume the function with $T_{t}$ and $\frac{S C_{t}}{H_{t}}$ is non-linear: $T_{t}=\left(\frac{S C_{t}}{H_{t}}\right)^{\theta}$, where the parameter $\theta \neq \alpha$ and $\theta \neq 0$. If $\theta=0, T_{t}$ would equal 1 , we don't consider this simple case. So, the production function (1) is also following: $Y_{t}=\left(\frac{S C_{t}}{H_{t}}\right)^{\theta} \cdot S C_{t}^{1-\alpha} \cdot H_{Y_{t}}^{\alpha}$.

Because $T_{t}$ is stable at average level along balanced growth path equilibrium, firms produce consumption goods under the condition of perfect competition. The first-order conditions to maximize the representative firm's profit function are:

$$
\begin{gathered}
P_{S C_{t}}=\frac{\partial Y_{t}}{\partial S C_{t}}=(1-\alpha) \cdot\left(\frac{S C_{t}}{H_{t}}\right)^{\theta-\alpha} \cdot \xi_{t}^{\alpha} \\
\omega_{H_{Y_{t}}}=\frac{\partial Y_{t}}{\partial H_{Y_{t}}}=\frac{\alpha}{\xi_{t}^{1-\alpha}} \cdot\left(\frac{S C_{t}}{H_{t}}\right)^{1-\alpha+\theta}
\end{gathered}
$$

Where $P_{S C_{t}}$ and $\omega_{H_{Y_{t}}}$ are respectively the marginal contribution rates of per unit scientific culture capital or per unit human capital to economic growth in process of goods production. $P_{S C}$ denotes the shadow price of scientific culture capital in terms of goods, $\omega_{H_{Y}}$ denotes the wage rate of per unit of human capital in goods production.

\subsection{Household Consumption}

Based on the framework of Barro (1990) and Turnvosky (2000), we postulate that the closed economy system consists of lots of fixed households with the identical and the infinite life, each household has only one person and population growth rate is zero.

Assume that the representative household uses all the income just for scientific culture capital investment. Therefore, the dynamic accumulation equation of scientific culture capital is:

$$
S \dot{C}_{t}=Y_{t}-C_{t}-\delta_{S C} \cdot S C_{t}
$$


Where $\delta_{S C} \geq 0$, is the depreciation rate of scientific culture capital. $C_{t}$ is consumption at $t$.

Based on equations (2.1) and (2.2), there is:

$$
Y_{t}=\omega_{H_{Y_{t}}} \cdot H_{Y_{t}}+P_{S C_{t}} \cdot S C_{t}
$$

By combining the above equation and Eq. (3), there is:

$$
S \dot{C}_{t}=\left(P_{S C_{t}}-\delta_{S C}\right) \cdot S C_{t}+\omega_{H_{Y}} \cdot\left(\xi_{t} \cdot H_{t}\right)-C_{t}
$$

$\xi_{t}$ is the proportion of human capital devoted to goods production in total human capital at $t$, so we take $1-\xi_{t}$ as the proportion of human capital devoted to producing new human capital. The dynamic accumulation equation of human capital is:

$$
\dot{H}_{t}=\left(\varphi \cdot R_{S C_{t}}\right) \cdot H_{t}+\mu \cdot\left(1-\xi_{t}\right) \cdot H_{t}
$$

Where $\mu>0$, is the productivity of that part of human capital devoted to producing new human capital. $R_{S C_{t}}=\frac{S \dot{C}_{t}}{S C_{t}}$, is the growth rate of scientific culture capital at $t . \varphi \in(0,1)$ denotes the influence level of scientific culture capital growth rate on the accumulation of human capital and can measure the complementarities between scientific culture capital and human capital. Sacco \& Segre (2009) found that cultural capital investment and human capital investment can be well linked by the complementarities.

Based on Eq. (4.2), when other conditions remain unchanged, the rapid growth of $R_{S C_{t}}$ can effectively improve the accumulation of human capital.

And then, there is the problem of the representative household:

$$
\max \int_{0}^{+\infty} \frac{C_{t}^{1-\sigma}-1}{1-\sigma} e^{-\rho t} d t
$$

Where $\sigma>1, \rho>0$; $\sigma$ is the reciprocal of intertemporal substitution elasticity of consumption, $\rho$ is the subjective discount rate.

The constraints are Eq. (4.1) and Eq. (4.2).

The infinite cross-sectional conditions are $\lim _{t \rightarrow+\infty} \lambda_{S C_{t}} \cdot S C_{t}=0$ and $\lim _{\mathrm{t} \rightarrow+\infty} \lambda_{\mathrm{H}_{\mathrm{t}}} \cdot \mathrm{H}_{\mathrm{t}}=0 . S C_{0}>0$ and $H_{0}>0$. $\lambda_{S C_{t}}$ and $\lambda_{H_{t}}$ are two co-state variables.

3.3 Competitive Equilibrium in the Long-Run

In this closed economy system, the competitive equilibrium in the long-run is that there exists a price make this set of elements $\{C, S C, H, \xi\}$ satisfy below conditions:

(1) For a certain $\{\xi\}$, firms will maximize their profits by choosing $\left\{S C, H_{Y}\right\}$;

(2) Households will maximize their welfare by choosing $\{C\}$ under the condition of satisfying their budget constraints;

(3) Capital markets are balanced;

(4) The budget constraints are all balanced at each period.

\section{Solving the Problem of Long-Term Equilibrium and Conclusion Analysis}

To consider the Hamiltonian Equation (Eq. $\mathbb{H})$ to solve the optimization problem.

$$
\mathbb{H}=\frac{C_{t}^{1-\sigma}-1}{1-\sigma} e^{-\rho t}+\lambda_{S C_{t}} \cdot\left[\left(P_{S C_{t}}-\delta_{S C}\right) S C_{t}+\omega_{H_{Y}}\left(\xi_{t} \cdot H_{t}\right)-C_{t}\right]+\lambda_{H_{t}}\left[\left(\varphi \cdot R_{S C_{t}}\right) H_{t}+\mu\left(1-\xi_{t}\right) H_{t}\right]
$$

The balanced growth path $\{C, S C, H, Y, \xi\}$ in economy system is a competitive equilibrium: the growth rates of $C$, $S C, H$ and $Y$ are constant and equal, we make the rate equal $R$. $\xi$ is also constant. So $P_{S C}$ and $\omega_{H_{Y}}$ are also constant.

The first-order conditions are following: 
Solving the partial derivative on the control variables: $\frac{\partial \mathbb{H}}{\partial c_{t}}=0$ and $\frac{\partial \mathbb{H}}{\partial \xi_{t}}=0$;

Solving the partial derivative on the state variables: $\frac{\partial \mathbb{H}}{\partial S C_{t}}=-\dot{\lambda}_{S C_{t}}$ and $\frac{\partial \mathbb{H}}{\partial H_{t}}=-\dot{\lambda}_{H_{t}}$.

By recalculating the above equations, we have:

$$
\begin{gathered}
\lambda_{S C_{t}}=C_{t}^{-\sigma} e^{-\rho t} \\
\frac{\lambda_{S C_{t}}}{\lambda_{H_{t}}}=\frac{\mu}{\omega_{H_{Y}}} \\
\frac{\dot{\lambda}_{S C_{t}}}{\lambda_{S C_{t}}}=-\left(P_{S C}-\delta_{S C}\right) \\
\frac{\dot{\lambda}_{H_{t}}}{\lambda_{H_{t}}}=-\left(\mu+\varphi \cdot R_{S C}\right)
\end{gathered}
$$

Eq. (5.2) is also written as $\lambda_{S C_{t}} \cdot \omega_{H_{Y}}=\lambda_{H_{t}} \cdot \mu$. And then solving the derivative both sides on $t: \dot{\lambda}_{S C_{t}} \cdot \omega_{H_{Y}}=\dot{\lambda}_{H_{t}} \cdot \mu$, so we have $\frac{\dot{\lambda}_{S C_{t}}}{\lambda_{S C_{t}}}=\frac{\dot{\lambda}_{H_{t}}}{\lambda_{H_{t}}}$ and Eq. (5.3) equals Eq. (5.4). Therefore, the Eq. (5.5) is following:

$$
P_{S C}=\mu+\varphi R+\delta_{S C}
$$

Based on Eq. (5.1), we have $-\sigma \frac{\dot{c}_{t}}{c_{t}}-\rho=\frac{\dot{\lambda}_{S C_{t}}}{\lambda_{S C_{t}}}$, then combining with Eq. (5.3) and Eq. (5.5), there is the equation $\frac{\dot{C}_{t}}{C_{t}}=\frac{\mu+\varphi R-\rho}{\sigma}$, and $\frac{\dot{C}_{t}}{C_{t}}=R$, so we have the below equations:

$$
\begin{gathered}
R=\frac{\mu-\rho}{\sigma-\varphi} \\
P_{S C}=\frac{\sigma\left(\mu+\delta_{S C}\right)-\varphi\left(\rho+\delta_{S C}\right)}{\sigma-\varphi}
\end{gathered}
$$

Based on Eq. (4.1) and Eq. (4.2), there are $R_{S C}=\left(P_{S C}-\delta_{S C}\right)+\xi \omega_{H_{Y}} \cdot \frac{H_{t}}{S C_{t}}-\frac{C_{t}}{S C_{t}}$ and $R_{H}=\varphi R_{S C}+\mu(1-\xi)$. And $R_{S C}=R_{H}=R$, then combining with Eq. (5.3), Eq. (5.4) and Eq. (6), we have $\xi \omega_{H_{Y}} \cdot \frac{H_{t}}{S C_{t}}-\frac{C_{t}}{S C_{t}}=-\xi \mu$ and $\xi=\frac{\mu(\sigma-1)+\rho(1-\varphi)}{\mu(\sigma-\varphi)}$.

Further, based on Eq. (2.1) and Eq. (7) and the value of $\xi$, we get the equilibrium ratio of scientific culture capital in the amount of human capital at the time of $t$ :

$$
\frac{S C_{t}}{H_{t}}=\left(\frac{(1-\alpha)(\sigma-\varphi)}{\sigma\left(\mu+\delta_{S C}\right)-\varphi\left(\rho+\delta_{S C}\right)}\right)^{\frac{1}{\alpha-\theta}}\left(\frac{\mu(\sigma-1)+\rho(1-\varphi)}{\mu(\sigma-\varphi)}\right)^{\frac{\alpha}{\alpha-\theta}}
$$

While equilibrium along the balanced growth path, the rates of income, consumption, scientific culture capital and human capital are the same, so we have:

$$
R_{Y}=R_{C}=R_{S C}=R_{H} \equiv R=\frac{\mu-\rho}{\sigma-\varphi}
$$

Next, it will analyze the effect of the depreciation rate $\left(\delta_{S C}\right)$ of scientific culture capital on the rate of economic growth $\left(R_{Y}\right)$. We will calculate the value of $\frac{\partial R_{Y}}{\partial \delta_{S C}}$. Based on Eq. (7), there is a finding: $\sigma-\varphi=\frac{\mu \sigma-\rho \varphi}{P_{S C}-\delta_{S C}}$ and $\frac{\partial P_{S C}}{\partial \delta_{S C}}=\frac{\sigma-\varphi}{\sigma-\varphi}=1$. Then combining $\sigma-\varphi=\frac{\mu \sigma-\rho \varphi}{P_{S C}-\delta_{S C}}$ and Eq. (9), we have $R_{Y}=\left(\frac{\mu-\rho}{\mu \sigma-\rho \varphi}\right)\left(P_{S C}-\delta_{S C}\right)$, therefore, 


$$
\frac{\partial R_{Y}}{\partial \delta_{S C}}=\left(\frac{\mu-\rho}{\mu \sigma-\rho \varphi}\right)\left(\frac{\partial P_{S C}}{\partial \delta_{S C}}-1\right)=0,
$$

It's proofed that the depreciation rate $\left(\delta_{S C}\right)$ of scientific culture capital has no effect on the rate of economic growth. Based on above those results, Eq. (7) is the shadow price of scientific culture capital in terms of goods while equilibrium in the long-run. Eq. (8) is the equilibrium ratio of scientific culture capital in the amount of human capital in the production process. When $\alpha \in(0,1), \varphi \in(0,1), \delta_{S C} \geq 0, \mu>0, \rho>0$ and $\sigma>1$, and suppose $\mu>\rho$, it is to ensure that the productivity of human capital producing new human capital is much larger than the subjective discount rate, which ensure $\xi \in(0,1)$, as well, the values of $R, P_{S C}$ and $\frac{S C_{t}}{H_{t}}$ are all strictly positive. Eq. (8) also shows that the value of the parameter $\theta$ (compare with $\alpha$ ) and the value of contribution rate $(\beta)$ of scientific culture capital on economic growth will influence the value of $\frac{S C_{t}}{H_{t}}$ while competitive equilibrium, but the values of $\theta$ and $\beta$ will not affect economic growth rate and the shadow price of scientific culture capital of consumption goods. Still ensuring $\mu>\rho$ and no changes of other parameters, Eq. (6) shows that the value of $\varphi$ (the effect of the growth rate of scientific culture capital on human capital accumulation) will affect the level of economic growth rate, and the greater the value of $\varphi$, the higher the economic growth rate when equilibrium along the balanced growth path.

\section{Conclusions}

New Economic Growth Theory found that human capital investment is more and more one of key factors in many possible elements which can promote economic growth and scientific culture is a core of human capital. Some studies in cultural economics field pointed out, in the long-run, investing culture will promote economic sustainable growth and the externality of cultural creative industries generally affects other production sections. Therefore, culture capital investment becomes one of important engines to maintain the long-run growth for economy.

Based on the framework by Barro (1990) and Turnvosky (2000), this paper constructed an economic growth model including the factor of scientific culture in the two sector economic system and analyzed the possible role on economic growth. The results are following: under the condition of no changes of other parameters, as well, ensuring the productivity of human capital producing new human capital is much larger than the subjective discount rate, the effect of the growth rate of scientific culture capital on human capital accumulation will determine the level of economic growth rate, and the greater the effect of the growth rate of scientific culture capital on human capital accumulation, the higher the economic growth rate when equilibrium along the balanced growth path.

\section{Acknowledgement}

This paper is funded by the projects "Monitoring \& Evaluation on National Science Popularization Capacity and Related Policies Research", "Study on Relationship between Scientific Culture and Economic Growth" and "Issues Study on Scientific Culture Construction" from China Research Institute for Science Popularization, we thanks them for supporting this study.

\section{References}

Barro, R.J. (1990). Government spending in a simple model of endogenous growth. Journal of Political Economy, 98(5), 103-125. https://doi.org/10.1086/261726

Costanza, R., \& Daly, H.E. (1992). Natural capital and sustainable development. Conservation Biology, 6(1), 34-46. https://doi.org/10.1046/j.1523-1739.1992.610037.x

Ernst Cassirer. (2013). An essay on man: An introduction to a philosophy of human culture (Chinese edition), translated by Gan Yang. Shanghai: Shanghai Translation Publishing House.

European Commission. (1998). Culture, the cultural industries and employment. Commission Staff Working Papers.

Florida, R. (2002). The rise of the creative class: and how it is transforming work, leisure, community and everyday life. New York: Basic Books.

Florida, R. (2005). The flight of the creative class: the new global competition for talent. London: Harper Collins. 
Godin, B., \& Gingras, Y. (2000). What is scientific and technological culture and how is it measured? A multidimensional model. Public Understanding of Science, 9(1), 43-58. https://doi.org/10.1088/0963-6625/9/1/303

Greffe, X. (1999). L'emploi culturel, a l'age du numerique. Anthropos, Paris, Economica.

Hanbury Brown. (1998). Scientific wisdom: Its relevance to culture and religion (Chinese edition), translated by Li Xingming. Liaoning: Liaoning Education Press.

Lawrence, E.H. (2006). The central liberal truth. Oxford University Press.

Lawrence, E.H., \& Samuel, H. (2000). Culture matters: Culture makes almost all the difference. New York: Basic Books.

Pickering, A. (1995). The Mangle of practice, time, agency, and science. Chicago and London: The University of Chicago Press.

Sacco, P.L., \& Segre, G. (2009). Creativity, cultural investment and local development: A new theoretical framework for endogenous growth. In Fratesi, U., \& Senn, L. (Eds.), Growth and innovation of competitive regions. Springer-Verlag, Berlin.

Sachs, J.D. (2005). The end of poverty. New York: Penguin.

Santagata, W. (2002). Cultural districts, property rights and sustainable economic growth. International Journal of Urban and Regional Research, 26(1), 9-23. https://doi.org/10.1111/1468-2427.00360

Throsby, D. (2008). The concentric circles model of the cultural industries. Cultural Trends, 17(3), 147-164. https://doi.org/10.1080/09548960802361951

Turnovsky, S.J. (2000). Fiscal policy, elastic labor supply, and endogenous growth. Journal of Monetary Economics, 45(1), 185-210. https://doi.org/10.1016/S0304-3932(99)00047-1

$\mathrm{Xi}, \mathrm{J}$. (2017). Report on the 19th national congress of communist party of China. Beijing: People's Publishing House.

Zweigenhaft, R.L. (1993). Prep school and public school graduates of Harvard: A longitudinal study of the accumulation of social and cultural capital. Journal of Higher Education, 64(2), 211-225. https://doi.org/10.1080/00221546.1993.11778423

\section{Notes}

Note 1. Data source: https://www.qianzhan.com/analyst/detail/220/170411-e19f6837.html, 2017-04-12.

Note 2. The book review written by Liu Xielin for the work Culture VS Technology Innovation: Cultural Comparison of Innovative Economy and Strategy Suggestion (Chinese Edition), Beijing: Intellectual Property Press, 2006.

Note 3. Since the mid-1980s, the New Growth Theory, mainly such as Romer (1986) and Lucas (1988), emphasized that technology progress is endogenous, capital accumulation and innovation are both important factors in promoting economic growth. See details: (1) Romer, P., "Increasing returns and long-run growth," Journal of Political Economy, Vol.94, No.5, 1986, (2) Lucas, R., “On the mechanism of economic development," Journal of Monetary Economics, Vol.22, No.1, 1988. 